\title{
Factors associated with impacts on quality of life after myocardial revascularization
}

\author{
Fatores associados a um impacto na qualidade de vida pós-revascularização miocárdica
}

Andressa Rodrigues de Souza ${ }^{1}$, Carla Lorenna Ferreira de Albuquerque ${ }^{1}$, Flávio Antônio Silva ${ }^{1}$, Regimar Carla Machado $^{1}$

Objective: to analyze the scientific evidence addressing factors associated with impacts on the quality of life of patients submitted to myocardial revascularization. Methods: integrative review, conducted in the databases Medical Literature Analysis and Retrieval System Online/Pubmed, Web of Science, Scopus, Science Direct, Latin American and Caribbean Health Sciences and Scientific Electronic Library Online. Results: eight studies were selected, mostly prospective cohorts, published in the years 2003 to 2013. The worsening of quality of life was determined by the instruments Medical Outcomes Short-Form-36 Health Survey - SF-36 and Item Health Survey - RAND-36, and the impact factors were age above 75, previous history of myocardial infarction or angina pectoris, and association of comorbidities such as diabetes mellitus and depression. Conclusion: factors such as extreme age and female gender were highlighted in the worsening of the quality of life of patients who had undergone myocardial revascularization.

Descriptors: Myocardial Revascularization; Quality of Life; Postoperative Period; Evaluation of Results of Therapeutic Interventions.

Objetivo: analisar evidências científicas que abordem fatores associados a um impacto na qualidade de vida de pacientes submetidos à revascularização miocárdica. Métodos: revisão integrativa, realizada nas bases de dados Medical Literature Analysis and Retrieval System Online/Pubmed, Web of Science, Scopus, Science Direct, Literatura Latino-Americana e do Caribe em Ciências da Saúde e Scientific Electronic Library Online. Resultados: selecionados oito estudos, predominando os coorte prospectivos, publicados nos anos de 2003 a 2013. A piora na qualidade de vida foi determinada pelos instrumentos Medical Outcomes Short-Form-36 Health Survey - SF-36 e Item Health Survey - RAND-36, e os fatores de impacto foram: idade $>75$ anos, sexo feminino, história prévia de infarto do miocárdio ou angina de peito e associação de comorbidades como diabetes mellitus e depressão. Conclusão: fatores como extremo de idade e sexo feminino se destacaram na piora da qualidade de vida de pacientes submetidos à revascularização do miocárdio.

Descritores: Revascularização Miocárdica; Qualidade de Vida; Período Pós-Operatório; Avaliação de Resultado de Intervenções Terapêuticas.

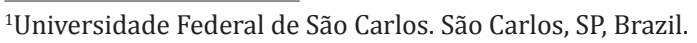

Corresponding author: Andressa Rodrigues de Souza

Rodovia Washington Luís, km 235 - SP-310. Universidade Federal de São Carlos - CEP: 13565-905. São Carlos, SP, Brazil. E-mail: andressaenf@gmail.com
} 


\section{Introduction}

The main therapeutic measures for cardiovascular diseases are drug therapy, physical activity, healthy diet and cardiac surgery. Myocardial revascularization stands out among the cardiac surgical procedures and is characterized as a procedure performed in the cases of coronary artery obstruction and has the purpose of unclogging and resuming the blood flow of these vessels ${ }^{(1)}$.

The main risk factors for coronary heart disease are systemic arterial hypertension, diabetes mellitus, dyslipidemia, age, gender, heredity, overweight and obesity, sedentary lifestyle and smoking. When these risk factors are present in the same patient, they increase the chances of cardiac complications, such as ischemias, thus requiring the performance of a myocardial revascularization ${ }^{(2)}$. However, this surgery may interfere in several aspects of the individual's life, with possible implications on his or her quality of life ${ }^{(3)}$.

The evaluation of the quality of life is a way of observing how the individual recognizes and perceives his/her health status. In this way, the use of this resource provides subsidies for conducting research, diagnostic tests or even investigative tests such as laboratory tests ${ }^{(4)}$.

The scientific literature has contradictory information on the improvement of the quality of life of the patients submitted to myocardial revascularization. These differences are mainly due to the different moments in which the studies were conducted, the therapeutic resources available and also the different tools used to evaluate patients' quality of life. Whereas there has been improvement of multiple components, such as functional capacity and physical limitation, vitality, emotional aspects, social aspects and general health status ${ }^{(5-8)}$, there is also the interference of some essential aspects in the maintenance of quality of life, such as the presence of intense postoperative pain ${ }^{(9)}$, postoperative pulmonary complications (pleural effusion, atelectasis, pneumothorax, pulmonary embolism, acute pulmonary respiratory failure and bronchopneumonia) ${ }^{(10)}$, cognitive deficit ${ }^{(11)}$, and psychological changes, such as anxiety and depres$\operatorname{sion}^{(12)}$.

Based on the professional practice, the nurses are the professionals responsible to perform the direct assistance to patients in the postoperative period. Due to this, studies on quality of life and clinical practice in the health services have been an important process for clinical decision-making and determination of the therapeutic benefit, especially after myocardial revascularization. This issue requires a reliable evaluation of the mechanisms that negatively affect quality of life in order to subsidize a planning of assertive interventions to promote patient well-being and to effectively contribute to the reduction of the number of readmissions and increase of the survival index of this clientele. Thus, the objective of this study was to analyze scientific evidence that addresses factors associated with impacts on the quality of life of patients submitted to myocardial revascularization.

\section{Methods}

This is an integrative review of the literature, covering six phases: 1) Identification of the theme and elaboration of the research question; 2) Sampling or search strategy in the literature; 3) Extraction of data from primary studies; 4) Evaluation of included studies; 5) Analysis of results; 6. Synthesis of knowledge and presentation of integrative review ${ }^{(13)}$.

Initially, the PICO (P-Population; I-Intervention; C-Comparison; O-Outcome) strategy was used according to the guidelines of the Preferred Reporting Items for Systematic Reviews and Meta-Analyzes (PRISMA) ${ }^{(14)}$. However, a modification was implemented in the acronym in order to answer and fill in the relevant fields to the elaboration of the guiding question of this review ${ }^{(15-16)}$, namely P-Population (Patients in the postoperative period of myocardial revascularization); I-Phenomenon of interest (Factors associated with a negative impact on the quality of life of patients submitted to myocardial revascularization); C - Study 
context (Patients followed for up to one year after the surgical procedure); O-Primary outcomes (Identification of the variables with the greatest impact on the quality of life of patients undergoing myocardial revascularization, measured quantitatively by validated scales) and Secondary outcomes (Prevention of physical and mental complications arising from factors that negatively impact quality of life and increase patients' morbidity and mortality rates).

Thus, the review question, based on the PICO strategy, was: What are the factors associated with a negative impact on the quality of life of patients undergoing myocardial revascularization, measured quantitatively by validated scales?

The studies were identified in six electronic databases: Medical Literature Analysis and Retrieval System Online (MEDLINE) via Pubmed, Web of Science, Scopus, Science Direct, Latin American and Caribbean Literature in Health Sciences (LILACS) and Scientific Electronic Library Online (SciELO). The advanced search strategy was conducted in August 2017, followed by removal of duplicated primary studies. In January 2018, the search strategy was updated in the respective electronic databases.

Descriptors of the controlled vocabularies of each database were selected, such as MeSH terms Pubmed and Descriptors in Health Sciences (DeCS) in
LILACS and SciELO, as well as uncontrolled descriptors (keywords) in Web of Science, SCOPUS and Science Direct. Subsequently, all controlled and uncontrolled descriptors were combined, using the "AND" and "OR" Boolean connectors. The search protocols are shown in Figure 1.

We considered the studies addressing the follow-up of aspects of quality of life in patients submitted to myocardial revascularization for a postoperative period of up to one year; without delimitation of temporal cut of the publications; in English, Spanish and Portuguese languages; containing validated quality of life scales; and presenting conclusive factors of negative impact of patients' quality of life after myocardial revascularization. We excluded studies with a qualitative approach; composed of patients in the age group from 0 to 18 years; duplicates; and those that did not include myocardial revascularization as the only cardiac surgical procedure.

For the selection of the studies, two independent reviewers (A.R.S and C.L.F.A) analyzed the titles and abstracts of the publications identified in the databases. The primary studies were classified as for inclusion, eventual inclusion and exclusion. In case of doubt or disagreement, a third reviewer (F.A.S) was asked to give an opinion on whether or not to include the study.

\begin{tabular}{|c|c|}
\hline Database & Search Protocol \\
\hline Medline/PubMed & $\begin{array}{l}\text { (Quality of Life OR Life Quality) AND (Myocardial Revascularization OR Internal mammary artery bypass grafts)) AND } \\
\text { Postoperative Period) AND (Treatment Outcome OR valuation of Results of Therapeutic Interventions) }\end{array}$ \\
\hline Web of Science & $\begin{array}{l}\text { ("Quality of Life" AND "Myocardial Revascularization" OR "Internal mammary artery bypass grafts" AND "Postoperative } \\
\text { Period" AND "Treatment Outcome") }\end{array}$ \\
\hline Science Direct & $\begin{array}{l}\text { ("Myocardial Revascularization" OR "Internal mammary artery bypass grafts") and ("Postoperative Period" AND "quality } \\
\text { of life") AND LIMIT-TO(contenttype, "JL,BS",'Journal") }\end{array}$ \\
\hline Scopus & $\begin{array}{l}\text { ("Quality of Life" AND “Myocardial Revascularization" OR "Internal mammary artery bypass grafts" AND “Postoperative } \\
\text { Period" AND “Treatment Outcome") AND (LIMIT-TO (DOCTYPE,"ar")) }\end{array}$ \\
\hline Lilacs & $\begin{array}{l}\text { ("qualidade de vida" AND "revascularização miocárdica") AND (instance:"regional") AND ( db:("LILACS") AND } \\
\text { limit:("humans" OR "female" OR "male" OR "aged" OR "adult") AND type:("article")) }\end{array}$ \\
\hline SciELO & "qualidade de vida" AND "revascularização miocárdica" AND type: ("research-article") \\
\hline
\end{tabular}

Figure 1 - Search protocols in the different databases used in the integrative review 
Data extraction and analysis of studies required the use of a form developed by the authors of this review, and two independent spreadsheets were built in Microsoft Word, which comprised information distributed in four domains: i) study identification: title, journal, year of publication, authors, country of study, language, type of publication; ii) objective and methodological characteristics; iii) primary and secondary outcomes; and iv) conclusions and clinical-epidemiological significance.
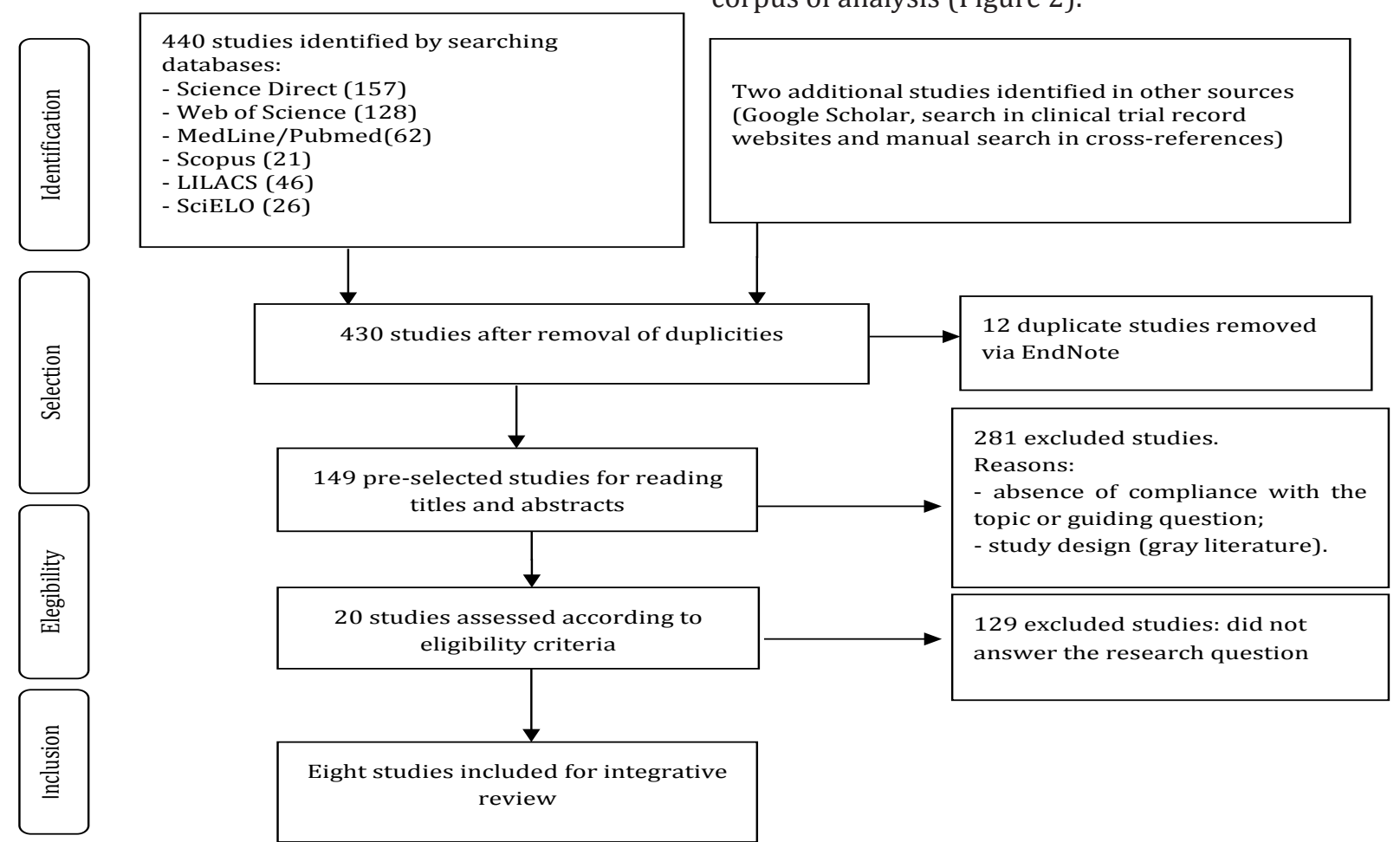

Eight studies included for integrative review

Figure 2 - Flowchart for the selection of studies, according to PRISMA recommendation ${ }^{(14)}$

\section{Results}

Initially, 440 articles were identified in the six databases and two were inserted after manual secondary searches via Google Scholar and/or in the references of the primary articles selected (cross-references). Thus, the search in the databases yielded 430 possible studies after the removal of the 12 duplicates. Most of the studies were excluded during the first screening (281), corresponding to studies without indexing in journals (gray literature); that did not address essential components of interest in this study, such as "quality of life" and "myocardial
A total of 20 articles were accessed for eligibility, of which 12 were excluded after exhaustive reading and detection of noncompliance with the inclusion criteria of this study (three articles did not evaluate patients' quality of life; two articles were Russian and one was German; four articles did not present conclusive factors of negative impact on patients' quality of life after myocardial revascularization; and two articles did not exclusively address myocardial revascularization surgery), resulting in eight articles for the corpus of analysis (Figure 2).

Two additional studies identified in other sources (Google Scholar, search in clinical trial record websites and manual search in cross-references) Reasons:

- absence of compliance with the topic or guiding question;

129 excluded studies: did not answer the research question revascularization"; and that exceeded the one-year period of follow-up of patients submitted to myocardial revascularization.

Table 1 presents an overview of the main features of the studies included in the integrative review $^{(17-24)}$. The studies were published between the years 2003 and 2013, originating in several countries, as an evidence of the worldwide interest in the theme "quality of life". Two studies were conducted in the United States of America ${ }^{(18,23)}$, two in Finland ${ }^{(21-22)}$, one in Brazil ${ }^{(17)}$, one in Norway ${ }^{(19)}$, one in Poland ${ }^{(20)}$, and one in $\operatorname{Iran}^{(24)}$. 
Table 1 - Characterization of studies included in the integrative review

\begin{tabular}{|c|c|c|c|c|}
\hline Authors/Country & $\begin{array}{c}\text { Sample (n) / Average } \\
\text { age (years) }\end{array}$ & $\begin{array}{l}\text { Quality of Life } \\
\text { Instrument }\end{array}$ & Evaluation/Period & $\begin{array}{l}\text { Level of } \\
\text { Evidence }\end{array}$ \\
\hline Nunes et al. ${ }^{(17)} /$ Brazil & $57 / 60$ & SF-36 & Preoperative and six months after surgery & 4 \\
\hline Martin el al. ${ }^{(18)} /$ USA & $496 / 64$ & SF-12 & Preoperative and six months after surgery & 4 \\
\hline Lie et al. ${ }^{(19)} /$ Norway & $185 / 62$ & SF-36 & Preoperative and six months after surgery & 4 \\
\hline Krzychet al. ${ }^{(20)} /$ Poland & $50 / 54$ & MacNew QoL & $\begin{array}{l}\text { Preoperative, 5-7 days, } 6 \text { weeks and } 10 \text { weeks } \\
\text { after surgery }\end{array}$ & 4 \\
\hline Järvinenet al. ${ }^{(21)} /$ Finland & $508 / 63$ & RAND-36 & Preoperative and 12 months after surgery & 4 \\
\hline 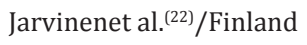 & $508 / 63$ & RAND-36 & Preoperative and 12 months after surgery & 4 \\
\hline Kereszteset al. ${ }^{(23)} /$ USA & $80 / 63$ & QLI (cardiac version) & Preoperative, one and three months after surgery & 4 \\
\hline Taghipouret al. ${ }^{(24)} /$ Iran & $112 / 61$ & SF-36 & 12 months after surgery & 6 \\
\hline
\end{tabular}

The selected studies were classified according to the level of evidence ${ }^{(16)}$, which were seven: 1) evidence presented in a systematic review or meta-analysis of randomized controlled clinical trials or clinical guidelines based on systematic reviews of randomized controlled trials; 2) evidence from a randomized controlled trial; 3) evidence from clinical trials without randomization; 4) evidence from cohort and case-control studies; 5) evidence from systematic review of descriptive and qualitative studies; 6) evidence of a single descriptive or qualitative study; 7) evidence from opinion of authorities and/or report of expert committees.

Quantitative approach was used in $100.0 \%$ of the studies. There was prevalence of prospective cohort studies, in seven out of the eight articles(87.5\%) ${ }^{(17-23)}$, and only a prospective descriptive observational study $(12.5 \%)^{(24)}$, which shows a predominantly longitudinal prospective profile chosen for the evaluation of the quality of life of individuals. Thus, the articles selected indicate, in great majority, level of evidence 4 , and although presenting average scientific evidence, according to the reference adopted in this study ${ }^{(16)}$, they constitute the most appropriate methodological design to be used in long-term lifestyle monitoring and/or personal satisfaction investigations.
The sample size of the included studies ranged from 50 to 508 patients, with a predominance of the age group around the age of 63 , characterizing the current scenario of prevalence of cardiovascular diseases, often with indication for myocardial revascularization surgery, in the third age.

The follow-up period of patients undergoing myocardial revascularization and the data collection on quality of life ranged from the preoperative period up to 12 months postoperatively. One study evaluated the moments of 5-7 days after surgery ${ }^{(10)}$, as well as 6 and 10 weeks $^{(20)}$; another evaluated the moments 1 and 3 months after surgery ${ }^{(23)}$; however, the evaluation periods that stood out were 6 months after surgery, adopted in three studies ${ }^{(17-19)}$, and 12 months, also adopted in three other studies ${ }^{(21-22,24)}$.

In this review, the type of instruments applied varied. Three articles used the SF-36 (Short-Form-36) instrument ${ }^{(17,19,24)}$, which is a widely used instrument in researches to obtain objective data on quality of life, with 36 questions addressing the general health status in domains that address physical function, physical components, body pain, general health, vitality, social function, emotional role and mental health; one article used a short version of SF-36, called the SF-12 (Short Form-12) ${ }^{(18)}$, with 12 easy-to-apply 
questions, covering the eight domains of the SF-36, but summarizing the domains in two topics, namely "summary of physical components" and "summary of mental components"; two articles derived from an original scientific study developed in Finland, in which quality of life is assessed with reference values targeting the Finnish population, applied the RAND-36 instrument ${ }^{(21-22)}$, which covers eight domains, such as general health, physical function, physical component, body pain, emotional well-being, emotional component, social function and energy; one study used the MacNew QoL scale ${ }^{(20)}$, related to heart disease, with 27 questions that cover emotional characteristics of individuals in 14 questions, as well as physical and social characteristics in 13 questions; and one article applied the cardiac version of the Quality of Life Index (QLI) instrument ${ }^{(23)}$, which addresses 32 items in four subscales of functional capacity and health, socioeconomic components, psychological/spiritual components, and family.

Among the factors associated with a negative impact on the quality of life of patients submitted to myocardial revascularization, the physical components intrinsic to the patient stand out, such as sex and age. The female sex was more susceptible to comorbidities at the time of cardiac surgery and is characterized, alone, as an independent predictor of poor postoperative quality of life ${ }^{(18)}$ by the lower levels of physical activity, vitality and general health status, as well as higher levels of shortness of breath and depression $^{(24)}$. Despite this, another study showed that males were more prone to depression, in such a way as to interfere in quality of life in the postoperative period of myocardial revascularization ${ }^{(17)}$.

Regarding the age component, it was found that extreme age (above 75 years) not only leads to higher rates of cardiac postoperative mortality and morbidity, but also to lower benefits of myocardial revascularization in terms of quality of life ${ }^{(22)}$.

A study assessing quality of life in the first postoperative days of myocardial revascularization, as well as a few weeks later, found that the quality of life deteriorated considerably in the first postoperative days, but had gradual improvement over time ${ }^{(20)}$, which leads us to conclude that the shortest time elapsed from surgery is an interference factor in the patient's quality of life. However, in the weeks after the surgery, the negative influences on quality of life were the presence of previous history of acute myocardial infarction and symptoms of angina, in addition to advanced age and preoperative risks.

When the assessment of quality of life was performed in the 6-month period after myocardial revascularization, it was established an association between worsening of the quality of life and the patient's status as "living alone", as well as association to admission due to myocardial infarction and presence of creatine kinase isoenzyme (CK-MB) in the blood serum. In the mental component, there was worsening of the quality of life when the patient had anxiety and/ or depression, and the presence of pleural drainage ${ }^{(19)}$.

After 12 months of myocardial revascularization, the studies showed that the patients presented worsening of some aspects evaluated in the instruments of quality of life, such as body pain, general health, vitality, social function and mental health ${ }^{(24)}$, and that diabetes mellitus was a factor associated with a negative impact on quality of life, since diabetic patients presented a slight reduction in quality of life in relation to non-diabetics ${ }^{(21)}$.

\section{Discussion}

The analysis of the studies included in this review provided relevant information about the assessment of quality of life of patients undergoing myocardial revascularization. Validated scales based on scientific evidence consist of objective quantitative data tools with different domains for this assessment.

Additionally, this review presents limitations related to the restricted number of studies with Brazilian patients. However, larger studies could possibly 
portray the negative impacts of myocardial revascularization on quality of life, considering the socioeconomic and cultural peculiarities inherent in the country.

Regarding the negative impact on quality of life, the intrinsic components of the patient, such as gender and age $\mathrm{e}^{(17-18,22)}$, stand out. A study showed similar results when comparing the female and the male genders in terms of reported quality of life after myocardial revascularization, as it mostly verified the susceptibility of women to greater postoperative complications ${ }^{(25)}$. Another study highlights the impact in the physical domain referring to the levels of physical activity, vitality and respiratory capacity ${ }^{(23)}$.

Particularly in terms of physical activity, a survey of 55 patients submitted to myocardial revascularization observed that those who performed physical activity before cardiac surgery had less hospitalization time and fewer postoperative complications, to the point that, contrarily, having a sedentary lifestyle in the preoperative period had a significantly negative impact on the physical aspect in the postoperative $\operatorname{period}^{(26)}$.

When assessing age as a reducing factor for the quality of life throughout the clinical recovery process, the patients in the extreme age group stand out, as reported in a study that approached patients over 75 years old, who obtained lower benefits by presenting higher postoperative mortality rates ${ }^{(22)}$. In view of this, the elderly population is usually carefully evaluated for the indication of myocardial revascularization in order to provide a more effective and safe recovery, with minimum interference in aspects related to the quality of life of this population ${ }^{(27)}$.

Other components associated with "female gander and extreme age" that were impacting on the quality of life of post-myocardial revascularization patients were comorbidities at the time of surgery, such as acute myocardial infarction, as reported in two studies of this review ${ }^{(19,21)}$. These studies showed that the patients evaluated within a few days after surgery and up to six months later had a strong influence on the previous history of acute myocardial infarction in the worsening of quality of life.

Diabetes mellitus was considered as a limiting component for the improvement of the quality of life after myocardial revascularization in one of the selected studies ${ }^{(21)}$. Similar data were found in another study in the literature that showed that diabetes was one of the most significant variables associated with impaired quality of life in the physical domain, with repercussions on the dimensions encompassing energy, mobility and pain ${ }^{(17)}$. However, for these patients, the literature demonstrates that surgery may be better in terms of quality of life when compared to clinical treatment, especially in insulin-dependent patients or who have undergone mammary artery grafts ${ }^{(28)}$.

It was verified that the quality of life may be worse in the first days after the surgery in relation to the preoperative period ${ }^{(20)}$. Such a finding can be attributed to the post-surgical recovery period, which is most often accompanied by severe pain, physical discomfort and insecurity, directly influencing quality of life. However, another study found divergent results, in which the evaluation of physical quality of life was worse before myocardial revascularization, with an improvement in the postoperative score ${ }^{(3)}$. This result can be justified by the improvement in daily functions previously performed with some degree of limitation.

Regarding the mental impact on the quality of life of patients submitted to myocardial revascularization, a study with a focus on the mental health highlighted the role of depression in the negative interference on the quality of life, mainly in the male patient ${ }^{(18)}$. For such indexes to be reduced, the study refers to the need for a greater follow-up and psychosocial intervention during the routine screening of all patients who are candidates for myocardial revascularization and more specifically to male patients.

The association of the factors presented in this review reinforces the conception that individuals undergoing myocardial revascularization experience several postoperative consequences that impact greatly 
on their quality of life. For this reason, nursing teams must pay attention to the way in which the people who experience myocardial revascularization continue their life after the procedure in order to facilitate the patient's adaptation to his/her new routine within the limits imposed by surgical treatment.

The success of the surgery depends on the immediate care provided by the health team in the transand postoperative, as well as on the way that the individual will lead his/her life after discharge. Therefore, the cardiac rehabilitation period is of fundamental importance for the individual to resume his/her activities, such as work, leisure activities and sexual life, and adopts an independent attitude even after performing the surgery.

The understanding of the determinant aspects of clinical worsening, often triggered by the reduction of the quality of life of the re-vascularized patient, helps health professionals identifying the interventions they should adopt towards this clientele, either through orientations or in the emotional support necessary in the rehabilitation phase, encouragement to seek autonomy and reconstruction of their identity after this impactful event, namely myocardial revascularization.

\section{Conclusion}

The present review points to the physical and mental factors that determine the worsening of the quality of life of patients undergoing myocardial revascularization, with emphasis on the patient's intrinsic components, such as extreme age (greater than 75 years) and female gender. In addition, the presence of comorbidities at the time of surgery, such as previous history of acute myocardial infarction, symptoms of angina, diabetes mellitus and depression may also negatively impact quality of life throughout the postoperative period.

\section{Collaborations}

Souza AR, Albuquerque CLF, Silva FA and Machado RC contributed to the conception and design, analysis and interpretation of data, article writing, critical review of intellectual content and final approval of the version to be published.

\section{References}

1. Silva BA, Calles ACN, Freire RF. Perfil dos pacientes em pós-operatório de cirurgia de revascularização do miocárdio em um hospital de Maceió. Cad Grad Ciênc Biol Saúde [Internet]. 2014 [citado 2018 abr. 13]; 2(2):67-76. Disponível em: https:// periodicos.set.edu.br/index.php/fitsbiosaude/ article/view/1500

2. Lima FET, Araújo TL, Lopes MVO, Silva LF, Monteiro ARM, Oliveira SKP. Fatores de risco da doença coronariana em pacientes que realizaram revascularização miocárdica. Rev Rene [Internet]. 2012 [citado 2018 mar 13]; 13(4):853-60. Disponível em: http://www.periodicos.ufc.br/ rene/article/view/4047/3173

3. Dal Boni AL, Martinez JE, Saccomann IC. Quality of life of patients undergoing coronary artery bypass grafting. Acta Paul Enferm. 2013; 26(6):57580. doi: http://dx.doi.org/10.1590/S010321002013000600011

4. Sampaio JKVR, Figueiredo Neto JA, Queiroz LLC, Sousa RML, Reis LMCB, Silva FMAM. Impacto na qualidade de vida pós-angioplastia coronariana ou revascularização do miocárdio. Rev Bras Cardiol [Internet]. 2013 [citado 2018 mar 13]; 26(5):33746. Disponível em: http://www.onlineijcs.org/ sumario/26/pdf/v26n5a05.pdf

5. Morais CCA, Vidal TMS, Batista BR, França EET, Carneiro Júnior J. Avaliação da capacidade funcional e da limitação física em sujeitos pós-revascularização miocárdica. Rev Bras Ci Saúde. 2014; 18(4):297-302. doi: http://dx.doi.org/10.4034/ RBCS.2014.18.04.03 
6. Gois CFL, Dantas RAS, Torrati FG. Qualidade de vida relacionada à saúde, antes e seis meses após a revascularização do miocárdio. Rev Gaúcha Enferm. 2009; 30(4):700-7. doi: http://dx.doi. org/10.1590/S1983-14472009000400017

7. Bittar OJNV. Qualidade de vida após revascularização do miocárdio. Rev Bras Cir Cardiovasc [Internet]. 1992 [citado 2018 mar 13]; 7(1):1-8. Disponível em: http://www.scielo.br/pdf/rbccv/ v7n1/v7n1a01

8. Takiuti ME, Hueb W, Hiscock SB, Nogueira CRSR, Girardi P, Fernandes F, et al. Quality of life after surgical myocardial revascularization, angioplasty or medical treatment. Arq Bras Cardiol. 2007; 88(5):537-44. doi: http://dx.doi.org/10.1590/ S0066-782X2007000500007

9. Fonseca GGP, Parcianello MK, Zamberlan C, Marinho MGR, Carmo DRP, Siqueira HCH. Pain in the post-operative of myocardial revascularization and its inter-relation with the quality of life. Rev Pesqui Cuid Fundam Online. 2013; 5(2):363644. doi: http://dx.doi.org/10.9789/21755361.2013v5n2p3636

10. Calles ACN, Lira JLF, Granja KSB, Medeiro JD, Farias AR, Cavalcanti RC. Pulmonary complications in patients undergoing coronary artery bypass grafting at a hospital in Maceio, Brazil. Fisioter Mov. 2016; 29(4):661-7. doi: http://dx.doi. org/10.1590/1980-5918.029.004.ao01

11. Carrazedo MA, Accetta GG, Pinto RASR, Costa FAA. Avaliação cognitiva em pacientes submetidos à revascularização cirúrgica cardíaca. Rev Bras Cardiol [Internet]. 2014 [citado 2018 mar 13]; 27(4):254-9. Disponível em: http://www.onlineijcs.org/english/sumario/27/pdf/v27n4a04.pdf

12. Lima FET, Araújo TL, Serafim ECG, Custódio IL. Nursing consultation protocol for patients after myocardial revascularization: influence on anxiety and depression. Rev Latino-Am Enfermagem. 2010; 18(3):331-8. doi: http://dx.doi. org/10.1590/S0104-11692010000300006

13. Mendes KDS, Silveira RCCP, Galvão CM. Revisão integrativa: método de pesquisa para a incorporação de evidências na saúde e na enfermagem. Texto Contexto Enferm. 2008; 17(4):75864.doi:http://dx.doi.org/10.1590/S010407072008000400018
14. Moher D, Liberati A, Tetzlaff J, Altman DG. The PRISMA group: preferred reporting items for systematic reviews and meta-analyses: the PRISMA statement. PLoS Med. 2009; 6(7):e1000097. doi: https://doi.org/10.1371/journal.pmed.1000097

15. Karino ME, Felli VEA. Enfermagem baseada em evidências: avanços e inovações em revisões sistemáticas. Ciênc Cuid Saúde. 2012; 11(suppl):11-5. doi: http://dx.doi.org/10.4025/cienccuidsaude.v11i5.17048

16. Melnyk BM, Fineout-Overholt E. Evidence-based practice in nursing $\&$ healthcare: a guide to best practice. Philadelphia: Lippincott Williams \& Wilkins; 2005.

17. Nunes JKVRS, Figueiredo Neto JAD, Sousa RMLD, Costa VLXDC, Silva FDMAM, Hora AFLTD, et al. Depression after CABG: a prospective study. Rev Bras Cir Cardiovasc. 2013; 28(4):491-7. doi: http://dx.doi.org/10.5935/1678-9741.20130080

18. Martin LM, Holmes SD, Henry LL, Schlauch KA, Stone LE, Roots A, et al. Health-related quality of life after coronary artery bypass grafting surgery and the role of gender. Cardiovasc Revasc Med. 2012; 13(6):321-7. doi: https://doi. org/10.1016/j.carrev.2012.09.002

19. Lie I, Arnesen H, Sandvik L, Hamilton G, Bunch EH. Predictors for physical and mental health 6 months after coronary artery bypass grafting a cohort study. Eur J Cardiovasc Nurs. 2010; 9(4):238-43. doi: http://dx.doi.org/10.1016/j. ejcnurse.2010.02.001

20. Krzych ŁJ, Woźnica A, Pawlak A, SkaryszJ, Eysymontt Z, Chromańska-Matera B, et al. Quality of life in young, professionally active men undergoing on-pump coronary artery bypass grafting-short-term follow-up results. Kardiol Pol [Internet]. 2009 [cited 2018 Mar. 13]; 67(10):1078-85. Available from: https://www. ncbi.nlm.nih.gov/pubmed/20017073

21. Järvinen O, Julkunen J, Saarinen $T$, Laurikka J, Tarkka MR. Effect of diabetes on outcome and changes in quality of life after coronary artery bypass grafting. Ann Thorac Surg. 2005; 79(3):819-24. doi: https://doi.org/10.1016/j. athoracsur.2004.08.030 
22. Järvinen $\mathrm{O}$, Saarinen T, Julkunen J, Huhtala $\mathrm{H}$, Tarkka MR. Changes in health-related quality of life and functional capacity following coronary artery bypass graft surgery. Eur J Cardiothorac Surg. 2003; 24(5):750-6. doi: https://doi. org/10.1016/S1010-7940(03)00413-5

23. Keresztes PA, Merritt SL, Holm K, Penckofer S, Patel $\mathrm{M}$. The coronary artery bypass experience: gender differences. Heart Lung J Acut Critic Care. 2003; 32(5):308-19. doi: https://doi.org/10.1016/ S0147-9563(03)00101-8

24. Taghipour HR, Naseri MH, Safiarian R, Dadjoo Y, Pishgoo B, Mohebbi HA, et al. Quality of life one year after coronary artery bypass graft surgery. Iran Red Crescent Med J [Internet]. 2011 [cited 2018 Mar. 13]; 13(3):17-1. Available from: https://www.ncbi.nlm.nih.gov/pmc/articles/ PMC3371947/

25. Amato VL, Timerman A, Paes AT, Baltar VT, Farsky PS, Farran JA, et al. Immediate results of myocardial revascularization. Comparison between men and women. Arq Bras Cardiol. 2004; 83(esp.):14-20. doi: http://dx.doi.org/10.1590/ S0066-782X2004001900004
26. Nery RM, Barbisan JN, Mahmud MI. Influence of the practice physical activity in the coronary artery bypass graft surgery results. Rev Bras Cir Cardiovasc. 2007; 22(3):297-302. doi: http:// dx.doi.org/10.1590/S0102-76382007000300005

27. Sá MPBDO, Lima LP, Rueda FGD, Escobar RRD, Cavalcanti PEF, Escobar MASD, et al. Comparative study between on-pump and off-pump coronary artery bypass graft in women. Rev Bras Cir Cardiovasc. 2010; 25(2):238-44. doi: ttp://dx.doi. org/10.1590/S0102-76382010000200018

28. Kalil RAK. Coronary artery surgery in patients with diabetes mellitus. Arq Bras Endocrinol Metab. 2007; 51(2):345-51. doi: http://dx.doi. org/10.1590/S0004-27302007000200026 